\title{
Electrical impedance tomography captures heterogeneous lung ventilation that may be associated with ineffective inspiratory efforts
}

Qing Pan ${ }^{1}$, Mengzhe Jia ${ }^{1}$, Huiqing $\mathrm{Ge}^{2^{*}}$ and Zhanqi Zhao ${ }^{3,4^{*}}$ (D)

\section{Dear editor,}

Patient-ventilator asynchrony (PVA) is common in patients receiving mechanical ventilation, which is due to mismatch between neural and mechanical inspiratory time. This occurs primarily when the triggering and cycling-off of ventilatory assistance are not synchronized with the patient's inspiratory efforts. Ineffective inspiratory effort during expiration (IEE) is one of the most frequent type of PVA [1], which is associated with worse clinical outcomes [2]. Despite the extensive investigations on its mechanisms and recognition, rare notice was put on the regional ventilation distribution during IEE or other types of PVA. Electrical impedance tomography (EIT) emerges as an effective tool to monitor the regional lung ventilation [3]. In this study, we aim to describe an EIT-based method to assess heterogeneous lung ventilation, which may be associated with IEE.

Synchronized EIT and ventilator waveform were recorded in three patients with acute exacerbation of chronic obstructive pulmonary disease using PulmoVista500 and V300 (Draeger Medical, Luebeck, Germany). Patients were intubated and ventilated under assist-control mode. The relative impedance changes in ventral and dorsal regions are denoted as $I_{\mathrm{V}}(t)$ and $I_{\mathrm{D}}(t)$, respectively.

\footnotetext{
*Correspondence: gehq@zju.edu.cn; zhanqi.zhao@hs-furtwangen.de ${ }^{2}$ Department of Respiratory Care, Regional Medical Center for National Institute of Respiratory Diseases, School of Medicine, Sir Run Run Shaw Hospital, Zhejiang University, Hangzhou, China

${ }^{3}$ Department of Biomedical Engineering, Fourth Military Medical University, 169 Changle Xi Rd, Xi'an, China

Full list of author information is available at the end of the article
}

A so-called regional intensity fraction (RIF) curve was calculated as

$$
\operatorname{RIF}(t)=\frac{\text { Normalized } I_{\mathrm{V}}^{\prime}(t)}{\text { Normalized } I_{\mathrm{D}}^{\prime}(t)},
$$

where $I^{\prime}(t)$ denotes the 1 st order derivative of $I(t)$. The normalization converts the $I^{\prime}(t)$ into the range between 0.1 and 1 for the feasibility of fractional calculation according to the following equation

$$
\operatorname{Norm} \cdot I^{\prime}(t)=\frac{\left(I^{\prime}(t)-\operatorname{Min}\right) \times(1-0.1)}{\operatorname{Max}-\operatorname{Min}}+0.1
$$

where Max and Min are the maximum and minimum value of $I^{\prime}(t)$. In order to examine the correlation between RIF and IEE events, the IEE events were visually inspected by a senior respiratory therapist with clinical experience $>10$ years based on the stored ventilator waveforms.

We analyzed 6022 breath cycles in total. The clinical expert annotated 2945 IEE cycles and 3077 non-IEE cycles. In the expiratory phase, non-IEE cycles do not exhibit a local maximum (Fig. 1a), whereas typical IEE cycles show a distinct one (Fig. 1b). RIF max $_{\text {indicates }}$ the peak in the expiratory phase. RIF $_{\text {min }}$ denotes the local minimum between $0.3 \mathrm{~s}$ after the start of expiration and the position of $\mathrm{RIF}_{\max }$. Delta RIF, defined as $\Delta \mathrm{RIF}=\mathrm{RIF}_{\max }-\mathrm{RIF}_{\min }$, was associated with IEE. By selecting a threshold of 0.25 for $\Delta$ RIF, which was defined by searching the optimal value between 0.1 and 0.4 with a step of 0.05 for highest correlation between the annotation and the $\Delta$ RIF-based identification, all the 2945 IEE original author(s) and the source, provide a link to the Creative Commons licence, and indicate if changes were made. The images or other third party material in this article are included in the article's Creative Commons licence, unless indicated otherwise in a credit line to the material. If material is not included in the article's Creative Commons licence and your intended use is not permitted by statutory regulation or exceeds the permitted use, you will need to obtain permission directly from the copyright holder. To view a copy of this licence, visit http://creativecommons.org/licenses/by/4.0/. The Creative Commons Public Domain Dedication waiver (http://creativeco mmons.org/publicdomain/zero/1.0/) applies to the data made available in this article, unless otherwise stated in a credit line to the data. 

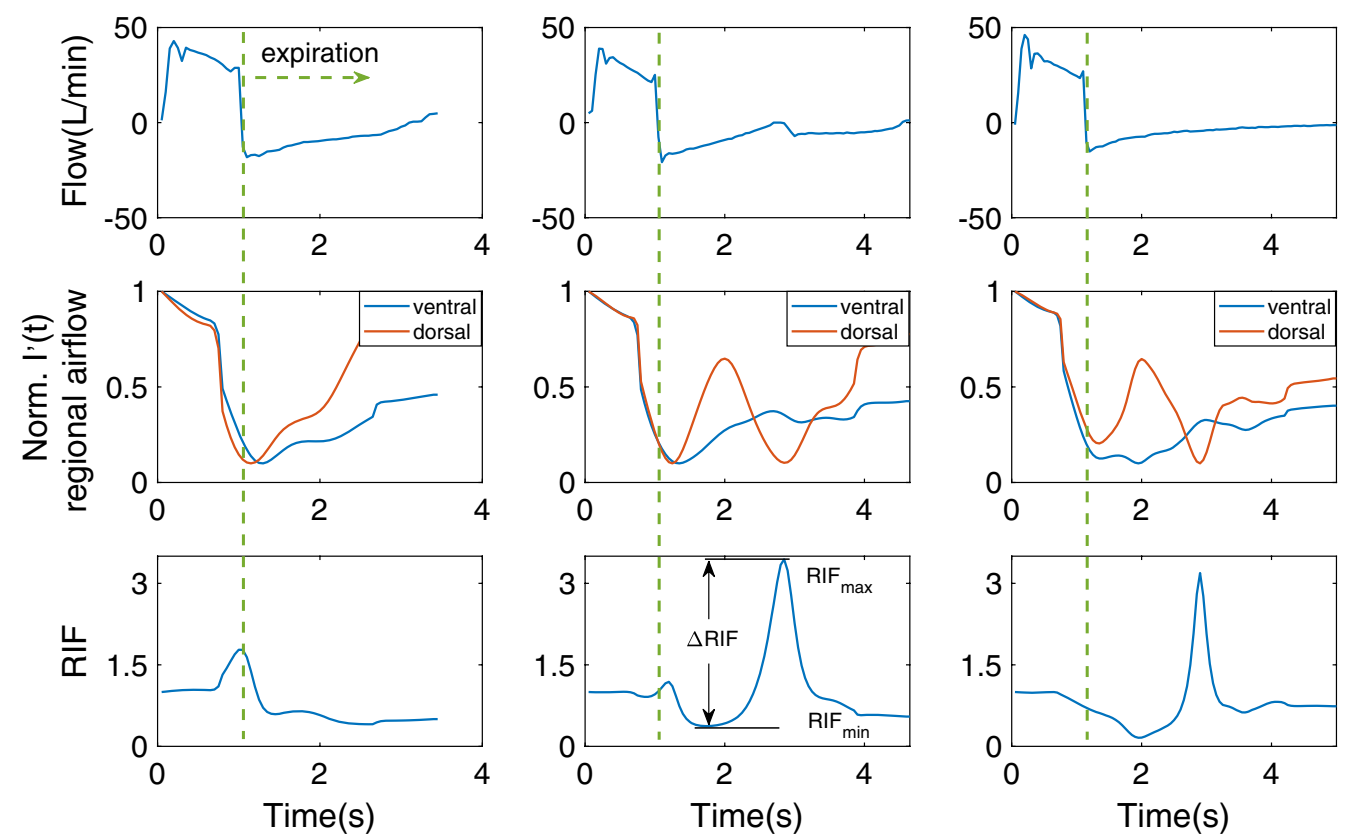

Fig. 1 The ventilator flow-time curves (first row), the normalized 1st order derivative of regional ElT intensity (second row), and the regional intensity fraction (RIF) curves (third row) of $\mathbf{a}$ non-IEE, $\mathbf{b}$ IEE, which coincided with the characteristic inspiratory flow observed in the flow-time curve, $\mathbf{c} I E E$, which was not able to be identified in the corresponding flow-time curve

cycles were correctly identified as IEE by EIT. Furthermore, 920 cycles labeled as non-IEE were recognized as IEE by the proposed EIT-based method. A typical cycle with discrepant results by the ventilator waveforms and the EIT is given in Fig. 1c. Characteristic inspiratory flow was not found in the flow-time curve. However, the RIF curve shows distinct IEE features, with a significant difference between the local maximum and minimum in the expiratory phase.

To our best knowledge, this is the first time to uncover that a particular regional lung ventilation pattern may be associated with the occurrence of IEE. The spontaneously ineffective breath results in more imbalanced ventilation distribution, characterized by higher portion in the dorsal regions. We suspected that patient's inspiratory effort triggered the redistribution of ventilation as proposed in previous studies [4]. However, some of these efforts were not transferred to the airway opening due to e.g. obstructive airway.

In conclusion, EIT is able to characterize the imbalanced ventilation that may be associated with IEE. It has the potential to discover IEE cycles without corresponding characteristics in the ventilator waveform. The findings require further validations with more subjects to confirm whether these cycles reflect asynchronous breath using esophageal pressure or electrical diaphragm activity, and if they will compromise the ventilatory support for the patients.

\section{Acknowledgements}

Not applicable.

\section{Authors' contributions}

$\mathrm{ZZ}, \mathrm{HG}$ and QP conceived and designed the study; QP and MJ performed the experiment, analyzed the data, and drafted the manuscript; $\mathrm{HG}$ and ZZ edited and revised the manuscript; all the authors approved the final version of manuscript. All authors read and approved the final manuscript.

Funding

The study is partially supported by National Natural Science Foundation of China (Grant Nos. 82070087, 52077216, 31870938).

Availability of data and materials

The datasets used and/or analyzed during the current study are available from the corresponding authors on reasonable request.

\section{Declarations}

\section{Ethics approval and consent to participate}

The ethics review board of Sir Run Run Shaw Hospital approved the study protocol (No. 20190916-16), and written informed consent was obtained from all participants before enrollment.

\section{Consent for publication}

Not applicable.

\section{Competing interests}

Zhanqi Zhao receives a consulting fee from Dräger Medical. Other authors declare no conflict of interest.

\section{Author details}

${ }^{1}$ College of Information Engineering, Zhejiang University of Technology, Hangzhou, China. ${ }^{2}$ Department of Respiratory Care, Regional Medical Center for National Institute of Respiratory Diseases, School of Medicine, Sir Run Run Shaw Hospital, Zhejiang University, Hangzhou, China. ${ }^{3}$ Department of Biomedical Engineering, Fourth Military Medical University, 169 Changle 
Xi Rd, Xi'an, China. ${ }^{4}$ Institute of Technical Medicine, Furtwangen University, Villingen-Schwenningen, Germany.

Received: 7 June 2021 Accepted: 9 August 2021

Published online: 21 August 2021

\section{References}

1. Blanch L, Villagra A, Sales B, Montanya J, Lucangelo U, Luján M, GarcíaEsquirol O, Chacón E, Estruga A, Oliva JC, et al. Asynchronies during mechanical ventilation are associated with mortality. Intensive Care Med. 2015:41(4):633-41.

2. Vaporidi K, Babalis D, Chytas A, Lilitsis E, Kondili E, Amargianitakis V, Chouvarda I, Maglaveras N, Georgopoulos D. Clusters of ineffective efforts during mechanical ventilation: impact on outcome. Intensive Care Med. 2017;43(2):184-91.

3. Borges JB, Suarez-Sipmann F, Bohm SH, Tusman G, Melo A, Maripuu E, Sandstrom M, Park M, Costa EL, Hedenstierna G, et al. Regional lung perfusion estimated by electrical impedance tomography in a piglet model of lung collapse. J Appl Physiol (1985). 2012;112(1):225-36.

4. Zhao Z, Peng SY, Chang MY, Hsu YL, Frerichs I, Chang HT, Moller K. Spontaneous breathing trials after prolonged mechanical ventilation monitored by electrical impedance tomography: an observational study. Acta Anaesthesiol Scand. 2017;61(9):1166-75.

\section{Publisher's Note}

Springer Nature remains neutral with regard to jurisdictional claims in published maps and institutional affiliations.
Ready to submit your research? Choose BMC and benefit from:

- fast, convenient online submission

- thorough peer review by experienced researchers in your field

- rapid publication on acceptance

- support for research data, including large and complex data types

- gold Open Access which fosters wider collaboration and increased citations

- maximum visibility for your research: over 100M website views per year

At BMC, research is always in progress.

Learn more biomedcentral.com/submissions 